\title{
A retail and consumer phase model for exposure assessment of Bacillus cereus
}

\author{
Maarten J. Nauta ${ }^{\mathrm{a}, *}$, Sonia Litman ${ }^{\mathrm{b}}$, Gary C. Barker ${ }^{\mathrm{c}}$, Frédéric Carlin ${ }^{\mathrm{d}}$ \\ ${ }^{a}$ Microbiological Laboratory for Health Protection, National Institute for Public Health and the Environment (RIVM), \\ P.O. Box 1, 3720 BA Bilthoven, The Netherlands \\ ${ }^{\mathrm{b}}$ Syndicat National des Fabricants de Plats Préparés Frais (SYNAFAP), 44 Rue d'Alésia, 75682 Paris Cedex 14, France \\ ${ }^{\mathrm{c}}$ Institute of Food Research (IFR), Norwich Research Park, Colney, Norwich NR4 7UA, UK \\ ${ }^{\mathrm{d}}$ Institute National de la Recherche Agronomique (INRA), UMR A408 Sécurité et Qualité des produits d'origine végétale, Site Agroparc, \\ 84914 Avignon Cedex 9, France
}

Received 5 December 2001; received in revised form 13 July 2002; accepted 29 August 2002

\begin{abstract}
An exposure assessment is conducted for psychrotrophic and mesophilic Bacillus cereus in a cooked chilled vegetable product. A model is constructed that covers the retail and consumer phase of the food pathway, using the output of a similar model on the industrial process as input. Microbial growth is the predominant process in the model. Variability in time and temperature during transport and storage is included in the model and different domestic refrigerator temperature distributions are compared. As an end point, probable levels of B. cereus colony forming units (cfu) in packages of vegetable purée are predicted at the moment the consumer takes the product from its refrigerator, that is prior to a cooking process. The psychrotrophic strain is predicted to end up above a threshold level of $10^{5} \mathrm{cfu} / \mathrm{g}$ in $0.9 \%$ to $6.3 \%$ of the vegetable purée packages, depending on domestic refrigerator temperature. Accounting for spoilage this reduces to $0.3 \%$ to $2.4 \%$. Even if the purée is stored at $4{ }^{\circ} \mathrm{C}$ in the domestic refrigerator and use-by-date (UBD) is respected, the threshold level may be passed. For the mesophilic strain the threshold level is rarely passed, but in contrast to the total viable count, the spore load at the end point is predicted to be higher than in the psychrotrophic strain. Our study illustrates how an exposure assessment model, which may be used in quantitative risk assessment, can integrate expertise in modelling, food processing and microbiology over the food pathway, and thus evaluate food safety, identify gaps in knowledge and compare risk management measures. As important gaps in knowledge, the lack of sporulation and germination models and data, validated non-isothermal growth models and a spoilage model useful for risk assessment are identified. Knowledge of the dose-response relationship is limited and does not allow a full risk assessment. It is shown that exposure can be lowered by lowering domestic refrigerator temperatures, and less so much by monitoring and withdrawing contaminated products at the end of industrial processing.
\end{abstract}

(C) 2002 Elsevier Science B.V. All rights reserved.

Keywords: Exposure assessment; Predictive microbiology; Bacillus cereus; Spoilage; Refrigeration

\section{Introduction}

* Corresponding author. Tel.: +31-30-2742805; fax: +31-302744434.

E-mail address: Maarten.Nauta@rivm.nl (M.J. Nauta).

In Europe, the production and sales of cooked chilled foods, also known as 'refrigerated processed 
foods of extended durability' (REPFEDs), are increasing (Hauben, 1999; Peck, 1999). For instance, the annual turnover of the cooked chilled food sector in France increased twofold between 1990 and 1994, and in 2000 the UK retail prepared chilled food market represented approximately $£ 5000$ million with a market value increase of $9 \%$ between 1999 and 2000 (Falconnet and Litman, 1996; Chilled Food Association, 2001). After receiving a mild heat treatment, these foods are to be stored in a chill chain from food manufacturer to the consumer. This treatment typically raises opportunities for pathogenic spore-forming bacteria like non-proteolytic Clostridium botulinum and Bacillus cereus, which may survive the heat treatment and grow at low temperatures (ICMSF, 1996; Lund and Peck, 2000).

A quantitative microbiological risk assessment (QMRA) approach is applied to study the potential impact of the increased popularity of REPFEDs on public health. QMRA is increasingly used to evaluate risks in the context of food safety (e.g. Notermans et al., 1997; Cassin et al., 1998). It offers a structured approach to assess risks associated with microorganisms in foods. If a risk model is constructed which describes the transmission of the hazard along the food pathway, the effects of intervention to lower the risk can be assessed and compared, thus assisting policy makers to come to decisions to increase food safety.

In the context of a collaborative EU-funded project on QMRA of spore-forming pathogens in REPFEDs (Carlin et al., 2000a), this study describes a model of $B$. cereus in the retail and consumer phase of the food pathway of a specific vegetable REPFED. Of these phases, the consumer phase is of particular interest, because it is less controlled than other phases of the food pathway. During transport or at home, consumer storage temperatures may be too high to maintain the chill chain and thus insufficient to prevent growth of (psychrotrophic) B. cereus.

As input, the model uses the results of a similar model that describes the industrial processing of this REPFED (Nauta, 2001). The exposure assessment ends at the moment the consumer takes the product from its refrigerator. As the knowledge of the doseresponse relationship for $B$. cereus is limited, the exposure assessment cannot be extended to a complete risk assessment. However, the impact of differ- ent processing steps on the final exposure can be put forward, and thus insight can be gained on the health effects of intervention at different processing steps.

The hazard studied is B. cereus, a pathogen for which both psychrotrophic strains and mesophilic strains are recognised. The actual harmful agent is not the bacterial cell, but the toxin that it may produce. Several types of toxin exist, of which diarrheal toxins are most commonly associated with food-borne illness (McKillip, 2000; Lund et al., 2000). In a REPFED containing vegetables, one typically finds diarrheal toxin producing strains (Choma et al., 2000). Production of this toxin most likely occurs in the small intestine of the host (Granum, 1997).

The objectives of the paper are to illustrate how this part of the food pathway may be modelled for an exposure assessment, to compare the exposure to psychrotrophic and mesophilic strains of B. cereus, to show the impact of post-industrial storage conditions on exposure, and to indicate what type of data and additional research are needed for QMRA that includes the consumer phase of the food pathway.

\section{Methods}

A risk model is set up following the Modular Process Risk Model (MPRM) methodology. This methodology is a variant of the Process Risk Model introduced by (Cassin et al., 1998) and has been described in detail elsewhere (Nauta, 2002, 2001; Anonymous, 2002). In the MPRM the transmission of the hazard is modelled by splitting up the food pathway into smaller steps (modules). Characteristically each module is assigned as one of six basic processes: growth, inactivation, mixing, partitioning, removal or cross-contamination. All of these may give rise to a change in prevalence $(P)$, unit size $(U)$ and/ or number of bacteria per unit $(N)$. An appropriate model is chosen to describe these changes, based on the purpose of the risk model and the available data. The risk model is a stochastic model, analysed by Monte Carlo simulation. Input and output are given in terms of probability distributions reflecting uncertainty or variability (Vose, 2000).

Typically, MPRM starts with a description of the food pathway and the processes that are relevant to 
assess the risk, not with collection of the available data. This may imply that parameters have to be defined in the process models for which the value cannot be estimated on the basis of scientific data. In that case food microbiology experts participating in the EU-funded project (Carlin et al., 2000a) were asked to give their expert opinion. These opinions were discussed in plenary meetings, until consensus was reached. Generally, the minimum (min), most likely $(\mathrm{ml})$ and maximum $(\max )$ values of the parameter, as assessed by the experts, were implemented as parameters for a BetaPert distribution (Vose, 2000), represented as BetaPert(min, $\mathrm{ml}$, max).

In the EU-funded project, the Monte Carlo simulation model described in this paper was compared with a Bayesian Belief Network approach (Jensen, 1996; Barker et al., 2000), which, quantitatively, gave almost identical results (data not shown).

Below, the food pathway is defined first, followed by a description of the models for the basic processes partitioning and growth, which are the only basic processes relevant in this particular model. They are combined in a spreadsheet model for exposure assessment.

\subsection{The food pathway}

The food pathway considered here starts at the end of industrial processing. The product of concern is a package of vegetable purée as produced by a European food manufacturer. This vegetable purée is made in large batches which have a fixed weight, $W_{\mathrm{b}}=300$ $\mathrm{kg}$. A batch is used to produce vegetable puré packages, with weight $W_{\mathrm{p}}=500 \mathrm{~g}$. Thus, the number of packages produced from one batch is $x=W_{\mathrm{b}} / W_{\mathrm{p}}=600$ packages (neglecting losses).

To predict growth of $B$. cereus further down the food pathway, information is required on the storage time and storage temperature. The vegetable purée packages are stored at the factory and transported to the retailers. Based on data from food manufacturers (Litman, 2000), it is assumed that the packages are stored and transported under strictly controlled time temperature conditions until they reach the retailers (that is $36 \mathrm{~h}$ at $4{ }^{\circ} \mathrm{C}$; small deviations from these constant conditions have only negligible effects (data not shown)). Next the packages are stored at three consecutive stages: (1) retail, (2) transport from retail to home, and (3) domestic refrigerator. The probability distributions of the storage characteristics are given in Table 1 and are explained below. These distributions describe 'per package' variability. This implies that it is assumed that packages originating from one batch experience independent time temperature regimes once they reach retail.

\subsubsection{Retail}

When the vegetable purée packages leave the factory, the use-by-date (UBD) on the packages is set at 21 days and is shown on the package. The food manufacturer indicated that in shops $80 \%$ are sold within 14 days and $20 \%$ between 14 and 21 days. All supermarkets remove products that reach the use-bydates (that is after 21 days). In the model, the storage time is implemented as $80 \%$ sold until 7 days before UBD, the rest sold in the last week before UBD, both with a uniform distribution.

Pierre (1996) presents French data for storage temperature at retail, with mean $4{ }^{\circ} \mathrm{C}$ and standard

Table 1

Overview of food pathway parameters

\begin{tabular}{|c|c|c|}
\hline Parameter & Description & Value \\
\hline$W_{\mathrm{b}}$ & batch weight & $300 \mathrm{~kg}$ \\
\hline$W_{\mathrm{p}}$ & package weight & $500 \mathrm{~g}$ \\
\hline$x$ & $\begin{array}{l}\text { number of packages } \\
\text { produced from } \\
\text { one batch }\end{array}$ & 600 \\
\hline$t_{0}$ & storage time until retail & 1.5 days \\
\hline$T_{0}$ & $\begin{array}{l}\text { storage temperature } \\
\text { until retail }\end{array}$ & $4{ }^{\circ} \mathrm{C}$ \\
\hline$t_{1}$ & storage time at retail & $\begin{array}{l}80 \% \text { : Uniform }(0,12.5) \\
\text { days } \\
20 \%: 12.5 \\
\text { + Uniform }(0,7) \text { days }\end{array}$ \\
\hline$T_{1}$ & $\begin{array}{l}\text { storage temperature } \\
\text { at retail }\end{array}$ & $\operatorname{Normal}(4,2.17){ }^{\circ} \mathrm{C}$ \\
\hline$t_{2}$ & transport time & $\operatorname{Gamma}(5.24,8.17) \min$ \\
\hline$T_{2}$ & $\begin{array}{l}\text { storage temperature } \\
\text { at transport }\end{array}$ & $\operatorname{BetaPert}(4,10,25){ }^{\circ} \mathrm{C}$ \\
\hline$t_{3}$ & $\begin{array}{l}\text { storage time in domestic } \\
\text { refrigerator }\end{array}$ & $\begin{array}{l}\text { Exponential }((21-\mathrm{PD}) / 3) \\
-\mathrm{PD} \text { days }\end{array}$ \\
\hline$T_{3}$ & $\begin{array}{l}\text { storage temperature in } \\
\text { domestic refrigerator }\end{array}$ & see Table 2 \\
\hline
\end{tabular}

Values are given either as constants or as probability distributions expressing variability per package.

$\mathrm{PD}=$ "date of purchase" $=t_{0}+t_{1}+t_{2}=1.5$ days + time at retail + transport time. 
deviation 2.17. This is implemented as a normal $\mathrm{N}(4$, 2.17) ${ }^{\circ} \mathrm{C}$ distribution.

\subsubsection{Transport from retail to home}

For transport time we use British data (Evans et al., 1991). It is found that transport time from retail to domestic refrigerator has a mean of $42.8 \mathrm{~min}$, with standard deviation 18.7. It is assumed that transport time is Gamma distributed, because the Gamma distribution is generally applied to describe (complex) waiting time distributions. Also, the Gamma distribution has no negative values and has a longer tail than the normal distribution. This results in a Gamma(5.24, 8.17) distribution for transport time.

The temperature during transport is largely unknown. Noting that these foods are generally not refrigerated during transport by the consumer, that there is an increase in temperature during transport to home and that this increase depends on many uncertain and variable factors, expert opinion from within the EU-funded project (based on, e.g. Evans, 1998) proposed a minimum $4{ }^{\circ} \mathrm{C}$, most likely $10{ }^{\circ} \mathrm{C}$ and maximum $25{ }^{\circ} \mathrm{C}$ for the effective temperature during transport. Differences in product temperature history profiles at various places throughout each packet of the purée are an additional source of variability, which are assumed to be included in this distribution.

\subsubsection{Domestic refrigerator}

Based on data from a French population survey (Babayou, 1995), the food manufacturer of the vegetable purée proposed that $5 \%$ of the packages are consumed after the UBD. To describe the distribution of times that the products are kept in the refrigerators, we assume an exponential distribution, which describes the waiting time between two events. It is assumed that consumer behaviour regarding the storage time is influenced by the UBD on the package. If PD is the day of purchase, UBD-PD is the time between purchase and use-bydate, that is the consumer storage time until the UBD is reached. Knowing that the $95 \%$ quantile of the exponential distribution lies at three times its mean, the exponential distribution which gives 5\% probability of a storage time exceeding the UBD has a mean $\mu=(\mathrm{UBD}-\mathrm{PD}) / 3$. The exponential distribution then describes the storage time after PD. As PD is variable, $\mu$ is variable too. The resulting distribution of storage times in the consumer refrigerator is derived by Monte Carlo simulation. It has a mean of 4.3 days and a median of 2.6 days. About $25 \%$ is eaten within 1 day of purchase, $81 \%$ within a week and $95 \%$ within 2 weeks. The mean date of consumption lies 8.5 days before UBD.

Data from different European countries (Table 2) allow us to construct distributions of domestic refrigerator temperatures. When a normal distribution is fitted to all the data points given, this results in a $\mathrm{N}(6.64,2.35){ }^{\circ} \mathrm{C}$ distribution of refrigerator temperatures in different private homes in Europe. As illustrated in Fig 1, the data seem to show some geographical trends: In Northern countries refrigerator temperatures are usually lower than in Southern countries. For comparison, we fitted normal distributions to data of a South European country (Sergelidis et al., 1997) and data of a North European country (Notermans et al., 1997) as well. For Southern Europe (two data points only) this resulted in $N(8.32,2.49){ }^{\circ} \mathrm{C}$, and for Northern Europe in $N(5.99,1.83){ }^{\circ} \mathrm{C}$.

In the exposure assessment we compare five different 'domestic refrigerator temperature' scenarios. The first three are those derived above, based on domestic refrigerator data. As alternatives, we consider two constant fixed refrigerator temperatures: 4 and $7{ }^{\circ} \mathrm{C}$.

Table 2

Reported values of temperatures in domestic refrigerators

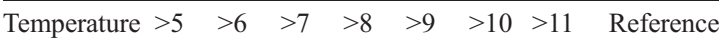

$\left({ }^{\circ} \mathrm{C}\right)$

\begin{tabular}{|c|c|c|c|c|c|c|c|c|}
\hline UK 1 & 0.71 & 0.54 & 0.33 & 0.19 & 0.07 & 0.02 & 0.01 & $\begin{array}{l}\text { Evans } \\
\text { et al., } 1991\end{array}$ \\
\hline UK 2 & 0.82 & 0.7 & 0.56 & 0.25 & 0.08 & 0.04 & 0.015 & $\begin{array}{l}\text { Johnson } \\
\text { et al., } 1998\end{array}$ \\
\hline NL & 0.7 & & 0.3 & & 0.03 & & 0.02 & $\begin{array}{l}\text { Notermans } \\
\text { et al., } 1997\end{array}$ \\
\hline France 1 & & 0.7 & & 0.41 & & & & AFF, 2000 \\
\hline France 2 & & 0.52 & & & & 0.18 & & $\begin{array}{l}\text { Anonymous, } \\
1999\end{array}$ \\
\hline France 3 & 0.8 & & & & & 0.06 & & $\begin{array}{l}\text { Guingois, } \\
2000\end{array}$ \\
\hline Greece & & & & 0.55 & & 0.25 & & $\begin{array}{l}\text { Sergelidis } \\
\text { et al., } 1997\end{array}$ \\
\hline
\end{tabular}

Values are the fraction of refrigerators with reported values higher than the one given in the heading (in ${ }^{\circ} \mathrm{C}$ ). For illustration see Fig 1. $\mathrm{UK}=$ United Kingdom, $\mathrm{NL}=$ Netherlands. 


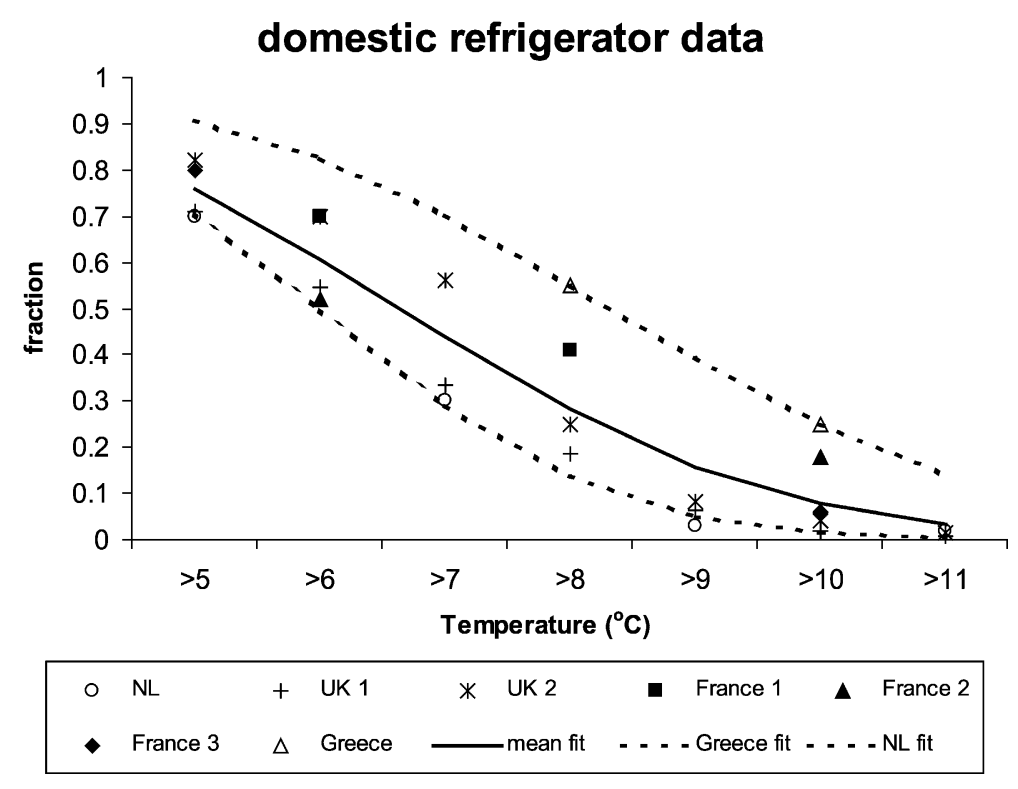

Fig. 1. The distribution of mean temperatures in domestic refrigerators in different European countries. Normal distributions (lines) are fitted to the data from Table 2 (markers). The solid line shows the 'Europe' temperature distribution, the fit through the mean of all data points. The dashed lines show the fits through the data from Greece (upper dashed line) and the Netherlands (NL) (lower dashed line), used in the model as temperature distributions for the 'South' and 'North' European scenarios.

These are the required temperatures for some perishable foods at retail in some EU member states (Anonymous, 1996).

\subsection{Partitioning}

In general, partitioning occurs when a large unit is split up into several smaller units. In the present food pathway this is the case when the large batch of vegetable purée is split up in $x=600$ packages. If it is assumed that the batch is well mixed, that all $x$ packages formed from one batch have an equal weight and that the $B$. cereus spores are randomly distributed over the batch, random sampling leads to a number of $N_{i}$ spores as a sample from a $\operatorname{Binomial}(N, 1 / x)$ distribution for one package $i$. (Here, $N$ is the total number of spores in the purée batch.) We neglect both spore clumping and the fact that the total number of spores in all packages should equal the total number in the batch, $\left(\sum N_{i}=N\right.$, see also Nauta, 2001; Nauta et al., 2001).

The prevalence $(P)$ may change from batch to packages if, by chance, one or more packages from a B. cereus-contaminated batch do not contain $B$. cereus spores. The probability of this event is

$P\left(N_{i}=0\right)=P_{0}=(1-1 / x)^{N}$

The number of noncontaminated packages is of particular relevance in the analysis, both because these packages no longer pose a risk, and because noncontaminated packages can be excluded from further spreadsheet model calculations. Neglecting dependence between packages, the number of noncontaminated packages, $x_{0}$, has a $\operatorname{Binomial}\left(x, P_{0}\right)$ distribution.

\subsection{Growth}

\subsubsection{A primary and a secondary growth model}

Predictive microbiology growth models should be used in risk assessment with careful consideration (Nauta, 2002). In general, predictive models produce point estimates. When a confidence interval is given, it is not clear whether this represents variability or uncertainty or both. Also, many models neglect variability between different strains of one species. This 
variability between strains can be relevant in the risk assessment of any microbial species. This is particularly so for the distinct categories of psychrotrophic and mesophilic strains of $B$. cereus, which, by definition, have very different growth characteristics. In the exposure assessment we therefore analyse both types of strains. As representatives we use strains INRA AVZ421 (mesophilic) and INRA AVTZ415 (psychrotrophic), which were isolated from REPFED made of vegetables (Choma et al., 2000). In this paper they are referred to as MESO and PSYC. Valero et al. (2000) studied the growth curves of these strains at different temperatures in nutrient broth and calculated the lag time $(\lambda)$ and maximum specific growth rate $(\mu)$ by fitting the Baranyi model to the data (Baranyi et al., 1993). We assume that growth in our model food was similar as in nutrient broth.

To model bacterial growth as a function of time and temperature, we have applied primary and secondary growth models (Whiting, 1995). As a primary model, in which the growth curve is given as a function of time, we use the lag exponential model

$\ln \left(N_{t}\right)=\ln \left(N_{0}\right)+\mu(t-\lambda)$

with $N_{t}$ the population size at time $t(t>\lambda), N_{0}$ the population size at $0 \leq t \leq \lambda, \mu$ the specific growth rate $\left(\mathrm{h}^{-1}\right)$ and $\lambda$ the lag phase duration (h).

This model is preferred to the Baranyi model mainly for reasons of simplicity. A comparison of both models showed that the variability between strains and the uncertainty of the estimates are much larger than the difference between the model predictions (data not shown).

As a secondary growth model for the effect of temperature we used the square root model (Ratkowsky et al., 1982), for both the specific growth rate and the lag phase.

$\mu=b\left(T-T_{\min , \mu}\right)^{2}$

$\lambda=c /\left(T-T_{\min , \lambda}\right)^{2}$

in which $T_{\min , \mu}$ is the minimum growth temperature with regards to $\mu, T_{\min , \lambda}$ is the minimum growth temperature with regards to $\lambda$, and $b$ and $c$ are scaling parameters. Note that these minimum growth temperatures are obtained by extrapolation of the regression line (Ratkowsky et al., 1982): after a transformation to
Table 3

Estimated values of the growth model parameters, using data from growth experiments with $B$. cereus in nutrient broth over the temperature range $5-30{ }^{\circ} \mathrm{C}$ (Valero et al., 2000)

\begin{tabular}{lllll}
\hline Strain & $b\left(\mathrm{~h}{ }^{\circ} \mathrm{C}^{2}\right)^{-1}$ & $T_{\min , \mu}\left({ }^{\circ} \mathrm{C}\right)$ & $c\left(\mathrm{~h}{ }^{\circ} \mathrm{C}^{2}\right)$ & $T_{\min , \lambda}\left({ }^{\circ} \mathrm{C}\right)$ \\
\hline MESO & $0.0025(0.0001)$ & $9.15(0.50)$ & $905(65)$ & $8.44(0.83)$ \\
PSYC & $0.00076(0.0001)$ & $0.04(1.14)$ & $1600(240)$ & $3.30(1.32)$
\end{tabular}

Mean and standard deviation (between brackets) as given are used in a normal distribution, which is assumed to describe within strain variability and is implemented as variability per industrial batch.

$\sqrt{ } \mu$ and $1 / \sqrt{ } \lambda$, i.e. Eqs. (3) and (4) are fitted to the growth data of Valero et al. (2000) by linear regression, yielding estimates of the parameters $b, T_{\min , \mu}, c$, and $T_{\min , \lambda}$ (see Table 3.) The uncertainty of the parameter estimates has been interpreted as variability between batches (or within strain variability) in the Monte Carlo simulations.

This secondary growth model is based on conditions with a constant temperature. However, in the exposure assessment we have to deal with the fact that the growth process continues while the temperature changes. For this purpose we have to apply a temperature function integration technique (Gill et al., 1991). When the exponential growth phase has been entered, the change in temperature may be incorporated by changing the growth rate to the one that corresponds to the new temperature. However, when the bacteria are still in the lag phase, the course of events is unclear. By the lack of a good alternative, we assume here that the fractions of the model lag times are summed up with changing temperature: If at storage step 1 , with temperature $T_{1}$ and storage time $t_{1}$, the lag phase duration is $\lambda_{1}$ (Eq. (4)) with $t_{1}<\lambda_{1}$, then at step 2,

$$
\begin{aligned}
\lambda_{2} & =c /\left(T_{2}-T_{\min , \lambda}\right)^{2}\left(1-t_{1} / \lambda_{1}\right) \\
& =\left(c-t_{1}\left(T_{1}-T_{\min , \lambda}\right)^{2}\right) /\left(T_{2}-T_{\min , \lambda}\right)^{2}
\end{aligned}
$$

and at step $j$

$\lambda_{j}=\left(c-\sum_{i=1}^{j-1} t_{i}\left(T_{i}-T_{\min , \lambda}\right)^{2}\right) /\left(T_{j}-T_{\min , \lambda}\right)^{2}$

Exponential growth starts after the remaining lag $\left(t_{j}-\lambda_{j}>0\right)$. Then, at the next step, $\lambda_{j+1}=0$.

Now, if we have an estimate of the initial population size $N_{0}$, we can predict the population size for 
each strain at each time temperature $(t, T)$ combination with the model:

if $t_{j}<\lambda_{j} \ln \left(N_{j}\right)=\ln \left(N_{j-1}\right)$

else $\quad \ln \left(N_{j}\right)=\ln \left(N_{j-1}\right)+b\left(T_{j}-T_{\min , \mu}\right)^{2}\left(t_{j}-\lambda_{j}\right)$

with $b, c, T_{\min , \mu}$ and $T_{\min , \lambda}$ variable per batch and $\lambda_{j}$ as defined above (Eq. (6)).

\subsubsection{Spoilage and maximum population density}

As microbial spoilage of the food product will lower the probability of consumption of a food product, it is important to incorporate spoilage (at the point that the consumer removes a packet of purée from the fridge) in the exposure assessment.

First, B. cereus itself may reach a level that implies spoilage. In the lag-exponential growth model (Eq. (2)), a stationary phase where the maximum population density (MPD) is reached is not included. Obtaining such a level may be correlated with spoilage. Therefore, based on expert opinion from within the EU-funded project, the MPD is included in the model as a threshold value. It is implemented as a per-batch variable with a BetaPert $(6,7.5,8.5) \log$ cfu/g distribution.

To our knowledge, a spoilage model for general spoilage flora in REPFEDs based on vegetables is not available. Spoilage data that are available (e.g. Carlin et al., 2000b) could not be used to derive such a model. As an alternative, we use the main characteristic of the square root model for the growth rate (Ratkowsky et al., 1982) to express the relative importance of time and temperature in a 'spoilage model', a very simple version of a time temperature integrator (Taoukis and Labuza, 1989; Taoukis et al., 1999).

Assuming that the minimum growth temperature is $0{ }^{\circ} \mathrm{C}$, the square root of the growth rate is linearly related to the temperature. Neglecting lag phase, the $\log$ of the concentration of the spoilage organism will be linearly related to time $\times$ temperature $^{2}$, expressed here as tTT. For changing temperature over time, tTT stands for the sum (or integral) of tTT for all time intervals. The available spoilage data show that spoilage will occur with high probability after 5 days at 20 ${ }^{\circ} \mathrm{C}$ or 20 days at $10{ }^{\circ} \mathrm{C}$, that is when $\mathrm{tTT}=2000$. It will occur with low probability after 10 days at $10{ }^{\circ} \mathrm{C}$, that is when $\mathrm{tTT}=1000$. These two values are therefore used to explore the effect of the potential occurrence of spoilage of the vegetable purée.

\subsubsection{Non-germination}

A complicating factor for a spore-forming pathogen like $B$. cereus is that it occurs in different states: spores and vegetative cells. Next to growth and inactivation, population dynamics of $B$. cereus is complicated by germination and sporulation. Of these, (non-) germination is particularly relevant in this study, because sporulation is not likely to occur in an unspoiled purée. In the exposure model we assume that the packages contain spores only because the purée has been pasteurised in the factory. After storage the packages may contain both spores and vegetative cells. These cell types may pose different risks to the consumer because survival and toxin production in the intestinal tract may be different.

Spore germination is assumed to take place when the minimum growth temperature as defined for the lag phase is exceeded. The growth phase starts immediately after germination, without a germination lag. If germination occurs, there is still a fraction of spores that does not germinate. This fraction is expressed as the probability that a spore does not germinate $\left(P_{\mathrm{sng}}\right)$, which is assumed to be variable per package. Based on various data sources (e.g. Pol et al., 2001) and expert opinion (R. Moezelaar, personal communication), minimum, most likely and maximum values for $P_{\text {sng }}$ are $0 \%, 0.1 \%$ and $30 \%$, implemented in a BetaPert distribution.

In the growth model as outlined above, it is assumed that $N$ is the sum of spores and vegetative cells. Although it is actually only the vegetative cells that multiply, so that a growth model considering vegetative cells only seems more realistic, this assumption has been made because the models are derived from and validated with experimental data on 'colony forming units', the sum of (viable) spores and cells.

\subsection{The exposure model}

The exposure model combines the food pathway characteristics with the basic models for partitioning and growth. It has been built as a spreadsheet model in 
Microsoft Excel with add on @Risk 4.0.5 (Palisade, Newfield). An overview of the model parameters and the distributions used is given in Tables 1-4. In one iteration of the Monte Carlo model, 100 packages of vegetable purée containing $B$. cereus originating from one batch are simulated. Per simulation 5000 iterations are run representing 5000 independent industrial batches and 500,000 packages. By doing so, the variability between batches and the variability between packages from one batch can be compared.

The input of the model is derived from the output of the model of the industrial process (Nauta, 2001). It implies that all industrial batches of vegetable purée are contaminated with $B$. cereus. The level of contamination is variable per batch. It is assumed that a batch is contaminated with one $B$. cereus strain only. As the frequency of contamination with either psychrotrophic or mesophilic strains (or both) is unknown, these two types are modelled separately. For the MESO the load in the industrial batch at the end of processing, $L_{0, \mathrm{MESO}}$ (log $\mathrm{cfu} / \mathrm{g})$, has a normal distribution, $N(0,0.67)$, and for PSYC, $L_{0, \mathrm{PSYC}}$, it follows $N(-2.4,0.67)$. The difference between the two is a consequence of a different heat resistance of the spores (Fernandez et al., 1999; Nauta, 2001). The initial number of spores

Table 4

Basic model equations and input values

\begin{tabular}{|c|c|c|}
\hline Parameter & Description & Value \\
\hline$L_{0, \text { MESO }}$ & $\begin{array}{l}\text { Initial spore } \\
\text { Load MESO }\end{array}$ & $\operatorname{Normal}(0,0.67) \log$ spore $/ \mathrm{g}^{\mathrm{b}}$ \\
\hline$L_{0, \text { PSYC }}$ & $\begin{array}{l}\text { Initial spore } \\
\text { Load PSYC }\end{array}$ & $\begin{array}{l}\text { Normal }(-2.4,0.67) \log \\
\text { spore/g }\end{array}$ \\
\hline$N_{0, \mathrm{~b}}$ & Spores per batch & $10^{L_{0}} W_{\mathrm{b}}$ spores $^{\mathrm{b}}$ \\
\hline$N_{i, 0}$ & $\begin{array}{l}\text { Initial number of } \\
\text { Spores per package } i\end{array}$ & $\operatorname{Binomial}\left(N_{0, \mathrm{~b}}, 1 / x\right)^{\mathrm{p}}$ \\
\hline$P_{0}$ & $\begin{array}{l}\text { Prevalence of packages } \\
\text { Without } B \text {. cereus } \\
\text { Spores after partitioning }\end{array}$ & $\begin{array}{l}\text { Binomial } \\
\left(x,(1-1 / x) N_{0, \mathrm{~b}}\right)^{\mathrm{b}}\end{array}$ \\
\hline$N_{i, j}$ & $\begin{array}{l}\text { Cfu per package } i \text { after } \\
\text { Food pathway step } j\end{array}$ & $\begin{array}{l}\text { see Eq. (7) and } \\
\text { Tables } 1 \text { and } 3^{p}\end{array}$ \\
\hline MPD & $\begin{array}{l}\text { Maximum population } \\
\text { Density }\end{array}$ & $\operatorname{BetaPert}(6,7.5,8.5)^{\mathrm{b}}$ \\
\hline$P_{\text {sng }}$ & $\begin{array}{l}\text { Probability of } \\
\text { Nongermination } \\
\text { Of a spore }\end{array}$ & $\operatorname{BetaPert}(0,0.001,0.3)^{\mathrm{p}}$ \\
\hline$S_{i}$ & $\begin{array}{l}\text { Spores left in the package } \\
\text { At the end point }\end{array}$ & $\begin{array}{l}\text { if } T_{\min , j}<T_{\min , \lambda} \text { at steps } j: \\
N_{i, 0} \text {, otherwise: } P_{\text {sng }} N_{i, 0}{ }^{\mathrm{p}}\end{array}$ \\
\hline
\end{tabular}

Variability distributions are sampled per industrial batch $\left(^{\mathrm{b}}\right)$ or per package $\left({ }^{\mathrm{p}}\right)$. per batch, $N_{0, \mathrm{~b}}=10^{L_{0}} W_{\mathrm{b}}$ spores, where $W_{\mathrm{b}}$ is the weight of the batch.

These $N_{0, \mathrm{~b}}$ spores are randomly distributed over the packages, modelled as a partitioning process. One hundred contaminated packages are followed in the simulation and the $\log$ of the number of viable organisms per package is computed. Growth is modelled as explained above, for each package independently. For all packages the model keeps track of the storage times and temperatures, to compare the predicted growth with potential spoilage and reaching the MPD. Also, storage time is compared with the time until the use-by-date is passed.

As a threshold level for $B$. cereus contamination of the product, we apply $10^{5} \mathrm{cfu} / \mathrm{g}$. This level is generally considered as the minimum level of concern to the consumer (Notermans et al., 1997; Granum and Baird-Parker, 2000). As a critical level we define a level $>10^{5} \mathrm{cfu} / \mathrm{g}$, given that the MPD is not reached, to incorporate the effect of spoilage by B. cereus. Note, however, that this threshold level is not considered as a threshold for illness as in the context of a doseresponse model. It is used as an alternative since the development of dose-response models for toxinogenic spore-forming microorganisms is complex and still in its infancy.

\section{Results and discussion}

\subsection{Exposure assessment}

The exposure modelling results are given in Table 5. It shows that PSYC reaches high levels most frequently. Due to a difference in sensitivity to heating, the initial $B$. cereus level is considerably lower for this strain, but its ability to grow at low temperatures allows an increase to critical levels. As illustrated in Fig. 2, the mean level of PSYC in the packages taken from the domestic refrigerator is still lower than that of MESO. However, the variability in growth in packages from one batch is much larger. This leads to a higher probability of passing the threshold level: for the average European domestic refrigerator temperatures, $3.3 \%$ of the vegetable purée packages are predicted to hold more than $10^{5}$ cfu/g of PSYC B. cereus. (Note that this is prior to a cooking process.) If corrected for MPD and spoilage, 
Table 5

Results of the exposure assessment for the psychrotrophic and mesophilic B. cereus strains and five domestic refrigerator temperature scenarios

\begin{tabular}{|c|c|c|c|c|c|c|c|c|c|c|}
\hline \multirow{2}{*}{$\begin{array}{l}\text { Strain } \\
\text { Temperature scenario }\end{array}$} & \multicolumn{5}{|l|}{ PSYC } & \multicolumn{5}{|l|}{ MESO } \\
\hline & South & Europe & North & $7^{\circ} \mathrm{C}$ & $4{ }^{\circ} \mathrm{C}$ & South & Europe & North & $7{ }^{\circ} \mathrm{C}$ & $4{ }^{\circ} \mathrm{C}$ \\
\hline Mean $\log N_{i}(\log \mathrm{cfu} / \mathrm{g})$ & -0.24 & -0.96 & -1.26 & -1.12 & -1.72 & 0.10 & 0.02 & 0 & 0 & 0 \\
\hline S.D. between batches & 1.04 & 0.89 & 0.82 & 0.93 & 0.65 & 0.68 & 0.67 & 0.67 & 0.67 & 0.67 \\
\hline S.D. within batches & 3.25 & 2.31 & 1.83 & 1.76 & 1.25 & 0.54 & 0.16 & 0.06 & 0.04 & 0.07 \\
\hline Mean $\log S_{i}(\log$ spores/g) & -2.64 & -2.64 & -2.64 & -2.64 & -2.64 & -1.2 & -1.1 & -1.1 & -1.1 & -1.1 \\
\hline B. cereus cfu in package & $73 \%$ & $73 \%$ & $73 \%$ & $73 \%$ & $73 \%$ & $100 \%$ & $100 \%$ & $100 \%$ & $100 \%$ & $100 \%$ \\
\hline B. cereus spores in package & $18 \%$ & $19 \%$ & $18 \%$ & $18 \%$ & $19 \%$ & $94 \%$ & $94 \%$ & $94 \%$ & $94 \%$ & $94 \%$ \\
\hline B. cereus growth & $40 \%$ & $31 \%$ & $27 \%$ & $32 \%$ & $16 \%$ & $8 \%$ & $2 \%$ & $1 \%$ & $0 \%$ & $0 \%$ \\
\hline$>10^{5} \mathrm{cfu} / \mathrm{g}$ & $6.3 \%$ & $3.3 \%$ & $2.1 \%$ & $2.1 \%$ & $0.9 \%$ & $0.4 \%$ & $0.1 \%$ & $0.0 \%$ & $0.0 \%$ & $0.0 \%$ \\
\hline Critical & $2.4 \%$ & $1.5 \%$ & $1.1 \%$ & $1.2 \%$ & $0.5 \%$ & $0.2 \%$ & $0.0 \%$ & $0.0 \%$ & $0.0 \%$ & $0.0 \%$ \\
\hline Critical, non-UBD & $2.0 \%$ & $1.2 \%$ & $0.8 \%$ & $0.8 \%$ & $0.5 \%$ & $0.2 \%$ & $0.0 \%$ & $0.0 \%$ & $0.0 \%$ & $0.0 \%$ \\
\hline Critical, non-spoiled + & $2.4 \%$ & $1.5 \%$ & $1.1 \%$ & $1.2 \%$ & $0.5 \%$ & $0.1 \%$ & $0.0 \%$ & $0.0 \%$ & $0.0 \%$ & $0.0 \%$ \\
\hline Critical, non-spoiled & $0.8 \%$ & $0.6 \%$ & $0.6 \%$ & $0.7 \%$ & $0.3 \%$ & $0.0 \%$ & $0.0 \%$ & $0.0 \%$ & $0.0 \%$ & $0.0 \%$ \\
\hline
\end{tabular}

Exposure is measured at the moment that the consumer takes the package of vegetable purée from the refrigerator. Mean values and standard deviations (S.D.) for $N_{i}$ and $S_{i}$ are the means of the (10 based) logs of the numbers found in packages contaminated with $B$. cereus (expressed per gram). Percentages are mean percentage of packages containing $B$. cereus; containing $B$. cereus spores; in which $B$. cereus has grown (i.e. the number of viable organisms per package has increased); passing the threshold level of $10^{5} \mathrm{cfu} / \mathrm{g}$; passing the critical level, that is $>10^{5} \mathrm{cfu} / \mathrm{g}$ given that the MPD is not reached; passing the critical level and not passing the UBD; passing the critical level and not passing tTT $=2000$; passing the critical level and not passing tTT $=1000$. (Note that $0.0 \%$ does not imply a zero risk, only that in less then $0.05 \%$ of the simulations the given criterion is met).

the probability of passing the critical level lies between $0.6 \%$ and $1.5 \%$. When the use-by-date is maintained this is $1.2 \%$.
Comparison of the different (distributions of) domes tic refrigerator temperatures shows that, as expected, the highest levels are predicted for the highest temper-

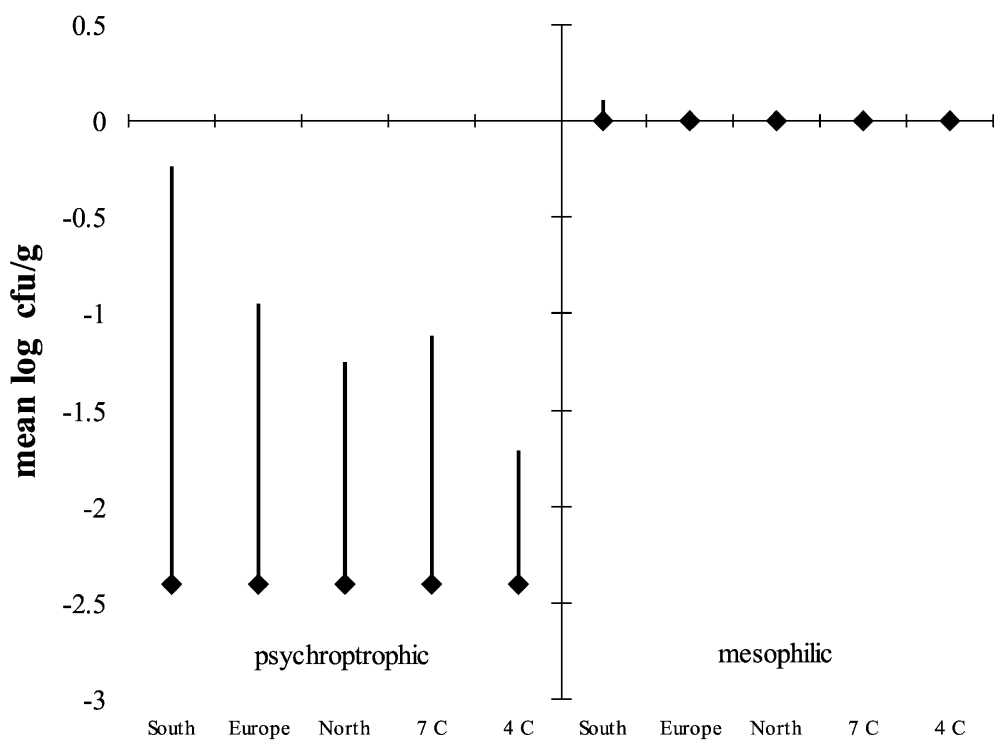

refrigerator temperature profile

Fig. 2. The change in the mean of the log concentration of B. cereus during the retail and consumer phase, for the psychrotrophic (PSYC) and mesophilic (MESO) strain, and for the five domestic refrigerator temperature scenarios. The diamond represents the mean initial concentration, the end of the line the mean $\log$ concentration at the end point. 
atures, i.e. the 'South' European scenario. For PSYC the probability of passing the threshold level $10^{5} \mathrm{cfu} / \mathrm{g}$ rises to $6.3 \%$, and when corrected for reaching the MPD and spoilage, the probability of passing a critical level is also larger. For other domestic refrigerator temperatures these probabilities are lower. However, even for the fixed $4{ }^{\circ} \mathrm{C}$ scenario, there is a $0.5 \%$ probability of passing the critical level before the UBD is passed. For MESO the level may only be too high for the 'South' European temperatures. For the others the probability of growth and the extent of growth are too low to reach critical levels. Note, however, that $0.0 \%$ in Table 5 does not imply a zero risk, only that in less then $0.05 \%$ of the simulations the given criterion is met.

The percentage of contaminated packages is $100 \%$ for MESO, but about $73 \%$ for PSYC. This is due to the higher initial levels of spores of MESO. As the MESO spores only rarely germinate in the purée, the final spore load is larger too. In fact, it may be that the spores are the actual hazard rather than the vegetative cells: since if the puree is heated before consumption this may inactivate vegetative cells, but not spores. As a consequence, mesophilic strains may pose a higher

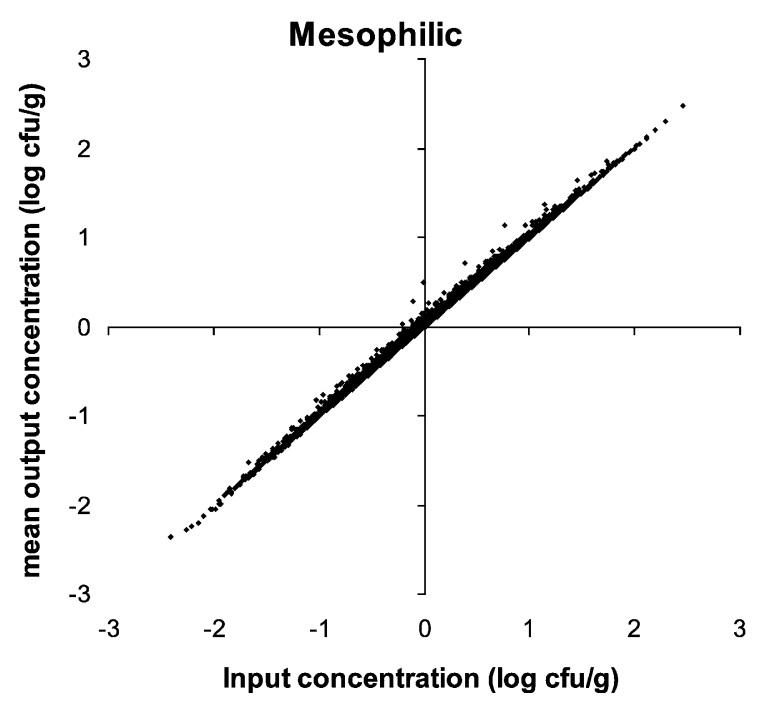

Fig. 3. Correlation between the concentration of the mesophilic $B$. cereus strain at the end of industrial processing and the mean of the $\log$ concentration in 100 packages at the end point, for 5000 simulated industrial batches, applying the 'European' domestic refrigerator temperature distribution. The value of the correlation coefficient $r^{2}=0.998$.

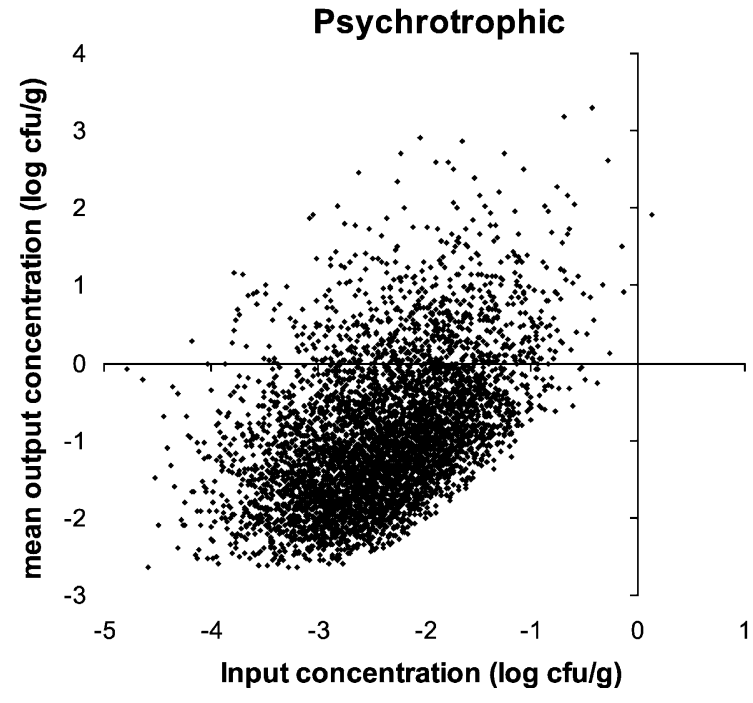

Fig. 4. Correlation between the concentration of the psychrotrophic $B$. cereus strain at the end of industrial processing and the mean of the log concentration in 100 packages at the end point, for 5000 simulated industrial batches, applying the 'European' domestic refrigerator temperature distribution. The value of the correlation coefficient $r^{2}=0.23$.

risk than psychrotrophic strains. Unfortunately, we were not able to extend the model to include a heating step by consumers and the next steps, consumption and dose-response. Required data on consumer behaviour and adequate models are not available.

The correlation between input and output concentrations are illustrated in Figs. 3 and 4. Here the mean of the logs of the concentration of the 100 simulated positive packages after domestic storage at the average 'European' temperatures is plotted against the (variable) initial (log of the) concentration of $B$. cereus in the industrial batches. It shows a strong correlation for MESO, for which growth is rare. For PSYC there is only little correlation: growth is frequent and the extent of growth is independent of the input. Similarly, the correlation between input and the percentage of critical packages is studied. This percentage of critical packages depends not only on the mean of, but also on the variability between, the packages originating from one batch. It appears that there is little correlation between the two, both for MESO and PSYC, with correlation coefficients $r^{2}<0.01$ and $r^{2}=0.16$, respectively (data not shown). The correlation for the MESO packages is low because growth occurs only in a very small 
fraction of the packages. Overall, this suggests that the level of $B$. cereus at the end of industrial processing is a poor predictor for health risks.

\subsection{Growth model}

The major part of the model is on B. cereus growth. Ideally, for exposure assessment growth has to be predicted for all relevant storage conditions and for all $B$. cereus strains that might be present in the food product. Models that are publicly available (Zwietering et al., 1996; USDA, 1998) do not include the variability between different strains or types of B. cereus. A 'worst case' model, although helpful to identify important steps in a food process, is insufficient for quantitative risk assessment, as it may wrongly suggest to be 'fail safe', and does not give an indication of the probability of ending up with an undesired situation. In this study we therefore used growth data from a psychrotrophic and a mesophilic strain in nutrient broth (Valero et al., 2000). Although this data set is only small, it is sufficient to illustrate how such growth data may be used in an exposure assessment. As the strains studied were isolated from a REPFED containing vegetables, this study was particularly applicable. Next, we had data on the inactivation characteristics of the same strains available, which allowed us to make an additional industrial process model (Nauta, 2001), and assess the differences in initial loads between PSYC and MESO. However, it should be realised that the growth data are experimental data of growth on a laboratory medium for a few constant temperatures. In this study they are applied to predict growth in real food, at varying temperatures, for a variety of strains.

Lag time prediction is complex as lag time duration may strongly depend on the initial physiological state of the cells and on the population size (Baranyi and Roberts, 1995; Baranyi, 1998). The 'reciprocal square root model' that we used is based on the assumption that the lag phase is inversely related to the specific growth rate (Smith, 1985; Baranyi and Roberts, 1994). It has been applied, for example, by Zwietering et al. (1994) and Koutsoumanis and Nychas (2000), and has been tested positively for Lactobacillus curvatus (Wijtzes et al., 1995).

The fact that the model holds two different values for minimum growth temperature $\left(T_{\min , \lambda}\right.$ and $\left.T_{\min , \mu}\right)$ may seem peculiar, as one might expect that $T_{\min , \mu}$ equals $T_{\min , \lambda}$. It seems, however, that these minimum growth temperatures are different, especially for PSYC. A reason for this may be the fact that germination (causing part of the lag) and growth are different processes (see below). Alternatively, it might be that the uncertainty about the limited data set is too large. It appeared that, if the two 'minimum growth temperature' parameters are set equal in the growth model (Eqs. (2)-(4)), the resulting model could not be fitted to the available data to an acceptable level. In the current model, the temperature should exceed the largest of the two minima to allow growth, so the largest of the two is to be interpreted as the actual minimum growth temperature.

\subsection{Spore germination}

The different states of $B$. cereus, as spores or vegetative cells, are a complicating factor. Usually growth experiments with $B$. cereus (as used for developing growth models) start with (ungerminated) spores and measure the total viable concentrations of vegetative cells and spores $(\mathrm{cfu} / \mathrm{ml})$ as a function of time. However, strictly speaking, growth is a combination of germination (from spore to vegetative cell) and growth (from vegetative cell to vegetative cells). For the prediction of growth alone, this need not be a problem. However, if a growth process is followed by inactivation, (for example if a cooked chilled food product is heated before consumption) we need to predict the number of spores that we end up with. These spores can be the product of both 'nongermination' and sporulation. Although several studies provide data on inactivation and germination of B. cereus spores (e.g. Johnson et al., 1982; Dufrenne et al., 1995; Pol et al., 2001), quantitative models to predict the number of spores after growth are not available to our knowledge. Therefore, in this study the spore load after growth is expressed as a simple nongermination fraction $P_{\mathrm{sng}}$, estimated by expert opinion, based on these data.

\subsection{Spoilage}

Spoilage is another complicating factor in a risk assessment of foods because conditions leading to critical levels of the hazard will usually favour spoilage, which will lower the probability of consumption. For a proper risk assessment, we therefore need a 
spoilage model that predicts the probability of spoilage of a given product at the point where it is removed from the domestic refrigerator, given its time temperature history, and the initial contamination by spoilage organisms. For some specific food products with specific distribution chains, such models are developed to assess shelf life and to optimise product quality (Taoukis and Labuza, 1989; Taoukis et al., 1999; Giannakourou et al., 2001). However, for the food product of interest here, a spoilage model was not available. Ideally, 'spoilage' is expressed in terms of probability of consumer acceptance as a function of time and temperature: not all consumers will react identically when a product 'smells badly' or is 'visibly spoiled'. In the end, consumption is critical for exposure.

In the current model we evaluate microbial spoilage by regarding the maximum population density (MPD) of $B$. cereus and the tTT-profile. When the MPD is reached, the concentration of $B$. cereus is high, between 6 and $8.5 \log \mathrm{cfu} / \mathrm{g}$. These levels need not necessarily imply spoilage of products by B. cereus, but as the conditions for which the MPD is reached will also favour spoilage, reaching MPD will be strongly associated with spoilage. As an alternative, we also look at the tTT profile as an indicator of spoilage. The threshold $\mathrm{tTT}=2000$ is regarded as a 'high probability of spoilage' value, and tTT $=1000$ is regarded as a 'low probability of spoilage' value. This simple model is based on some simple arguments. It aims to illustrate how a spoilage model can be used in a risk assessment, and gives a clue about the potential impact of spoilage. As an example, the results of PSYC 'South' show that large probability of packages with concentrations of $B$. cereus above the threshold level $(6.3 \%)$, is associated with a high probability of spoilage $(8.7 \%$ tTT $>1000)$, and a relatively high probability of reaching a critical level without spoilage $(0.8 \%)$.

\section{Conclusions}

This study illustrates how the retail and consumer phase of the food pathway can be modelled by linking currently available predictive models and data. It shows that improved growth models are required for QMRA purposes. The models used have not been validated for the conditions to which they are applied here, and hold assumptions that are disputable, both regarding secondary growth modelling, germination and spoilage. Nevertheless, with these models and data, we have been able to include several sources of variability and to predict the probability and the extent of growth of $B$. cereus in a vegetable product after industrial processing, as needed for QMRA.

In the assessment, five domestic refrigerator temperature scenarios are compared. In South European countries temperatures are higher, and, as a consequence, predicted levels of $B$. cereus are higher. It should be stressed that this finding is based on limited data, so that it is only preliminary. Also, the assessment shows that a constant domestic refrigerator temperature of $4{ }^{\circ} \mathrm{C}$ may not be sufficient to prevent $B$. cereus to grow to a critical level, even if the UBD is respected: higher temperatures during retail and transport may induce growth and according to the model, subsequent growth below $4{ }^{\circ} \mathrm{C}$ is not always excluded.

There is quite some uncertainty attending the model predictions. It is for example uncertain to what extent the models used are representative for variable (psychrotrophic and mesophilic) strains and products. Additionally, due to a lack of data, some assumptions and parameter estimates had to be based on estimates of experts. Next, time and resources did not allow validation of the models used. This implies that the value of the quantitative predictions should be handled with reservation. Nonetheless, they give a good indication of what should be expected, based on present knowledge in the fields of food microbiology and mathematical modelling.

It appears that the $B$. cereus level at the end of industrial processing is a bad predictor for high levels at the moment the package is taken from the refrigerator by the consumer. Although the initial level is strongly correlated with the mean level of packages from one batch for the mesophilic strain (see Fig. 3), these are generally low levels. For psychrotrophic strains that reach higher levels, this correlation is small (see Fig. 4). For both strain types, initial levels are hardly correlated with probability of reaching a critical level in a package.

The effect of the post-industrial part of the food pathway is therefore significant for the level of exposure. Monitoring for B. cereus at the end of industrial processing, or withdrawing the most contaminated packages at this point, will have little impact on the 
final exposure of the population. Next to intervention aiming at the ingredients added to the purée at industrial processing to reduce the spore load (Nauta, 2001), controlling refrigerator temperatures will be a better strategy to decrease the level of exposure to consumers. This strategy should mainly be aimed at the domestic refrigerators, where temperature abuse will be most frequent: unlike temperatures in a professional setting, it cannot be controlled by legislation.

\section{Acknowledgements}

The present study was part of a project financially supported by the Commission of the European Communities, Agriculture and Fisheries (FAIR) specific RTD programme CT97-3159. The participants of this project are acknowledged for providing their expert opinions and valuable discussion during the progress meetings. The authors are especially grateful to the food manufacturer that was willing to provide detailed information on the food pathway of the product considered in this study. Due to both identified and unidentified uncertainties, the results presented in this paper may in no way be related to the safety and quality of any of their products. The authors thank Roy Moezelaar, Arie Havelaar, Frans van Leusden and Mike Peck for valuable comments on the manuscript.

\section{References}

AFF, 2000. Recommandations de l'AFF concernant la conservation des denrées réfrigérées au niveau des ménages. Association Française du Froid (in French).

Anonymous, 1996. Abstracts of Report to the European Commission. Studies Relating to Temperature Control. Task SCOOP/ $\mathrm{MICR} / 2.2$.

Anonymous, 1999. Enquête INCA 1998-1999. Risques microbiologiques et pratiques d'achat, de transport et de stockage des aliments. Notre Alimentation 22, 7.

Anonymous, 2002. Risk assessment of food borne bacterial pathogens: quantitative methodology relevant for human exposure assessment. European Commission, Preliminary Report. http://www.europa.eu.int/comm/food/fs/sc/ssc/out252_en.pdf.

Babayou, P., 1995. Nutrition et hygiène alimentaire: attitudes et croyance des ménagères en 1995. Collection des Rapports No. R164 (in French) 140 pp.

Baranyi, J., 1998. Comparison of stochastic and deterministic concepts of bacterial lag. Journal of Theoretical Biology 192, $403-408$.
Baranyi, J., Roberts, T.A., 1994. A dynamic approach to predicting bacterial growth in food. International Journal of Food Microbiology 23, 277-294.

Baranyi, J., Roberts, T.A., 1995. Mathematics of predictive food microbiology. International Journal of Food Microbiology 26, $199-218$.

Baranyi, J., Roberts, T.A., McClure, P., 1993. A non-autonomous differential equation to model bacterial growth. Food Microbiology 10, 43-59.

Barker, G.C., Malakar, P., Peck, M.W.Thermal inactivation of bacterial spores: a Bayesian belief representation. In: Van Impe, K., Bernaerts, K. (Eds.), 3rd International Conference on Predictive Modelling in Foods, Leuven, Belgium. Kuleuven/Biotech, Leuven, Belgium, pp. 92-94.

Carlin, F., Girardin, H., Peck, M.W., Stringer, S., Barker, G., Martinez, A., Fernandez, P., Waites, W.M., Movahedi, S., Van Leusden, F., Nauta, M.J., Moezelaar, R., Del Torre, M., Litman, S., 2000a. A FAIR collaborative programme: research on factors allowing a risk assessment of spore-forming pathogenic bacteria in cooked chilled foods containing vegetables (FAIR CT97-3159). International Journal of Food Microbiology 60, $117-135$.

Carlin, F., Guinebretiere, M.H., Choma, C., Pasqualini, R., Braconnier, A., Nguyen-The, C., 2000b. Spore-forming bacteria in commercial cooked, pasteurised and chilled vegetable purées. Food Microbiology 17, 153-165.

Cassin, M.H., Lammerding, A.M., Todd, E.C.D., Ross, W., McColl, R.S. 1998. Quantitative risk assessment for Escherichia coli O157:H7 in ground beef hamburgers. International Journal of Food Microbiology 41, 21-44.

Chilled Food Association, 2001. UK retail chilled prepared food market: 2001, 2000 and 1999 (http://www.chilledfood.org.).

Choma, C., Guinebretiere, M.H., Carlin, F., Schmitt, P., Velge, P., Granum, P.E., Nguyen-The, C., 2000. Prevalence, characterization and growth of Bacillus cereus in commercial cooked chilled foods containing vegetables. Journal of Applied Microbiology $88,617-625$.

Dufrenne, J., Bijwaard, M., te Giffel, M., Beumer, R., Notermans, S., 1995. Characteristics of some psychrotrophic Bacillus cereus isolates. International Journal of Food Microbiology 27, $175-183$.

Evans, J., 1998. Consumer perceptions and practice in the handling of chilled foods. In: Ghazala, S. (Ed.), Sous Vide and Cook Chill Processsing for the Food Industry. Aspen Publishers Inc., Gaithersburg, Maryland, USA, pp. 1-24.

Evans, J.A., Stanton, J.I., Russell, S.L., James, S.J., 1991. Consumer Handling of Chilled Foods: A Survey of Time and Temperature Conditions Ministry of Agriculture, Fisheries and Food, Bristol, UK.

Litman, S., 1996. Le marché des produits sous vide. Proceedings of the Second European Symposium on Sous Vide. ALMA, Leuven, pp. 231-238.

Fernandez, A., Ocio, M.J., Fernandez, P., Rodrigo, M., Martinez, A., 1999. Application of non-linear regression analysis to the estimation of kinetic parameters for two enterotoxigenic strains of Bacillus cereus spores. Food Microbiology 16, 607-613.

Giannakourou, M.C., Koutsoumanis, K., Nychas, G.J., Taoukis, 
S., 2001. Development and assessment of an intelligent shelf life decision system for quality optimization of the food chill chain. Journal of Food Protection 64, 1051-1057.

Gill, C.O., Jones, S.D.M., Tong, A.K.W., 1991. Application of a temperature function integration technique to assess the hygienic adequacy of a process for spray chilling beef carcasses. Journal of Food Protection 54, 731-736.

Granum, P.E., 1997. Bacillus cereus. In: Doyle, M.P., Beuchat, L.R. Montville, T.J. (Eds.), Food Microbiology. Fundamentals and Frontiers. ASM Press, Washington, DC, pp. 327-336.

Granum, P.E., Baird-Parker, A.C., 2000. Bacillus cereus. In: Lund, B.M., Baird-Parker, A.C., Gould, G.W. (Eds.), The Microbiological Quality and Safety of Food, vol. II, Aspen Publishers, Gaithersburg, pp. 1029-1039.

Guingois, S., 2000. Industriels et distributeurs face au défi du froid. LSA 1666, 34-35.

Hauben, K., 1999. Sous vide cooking: state of the art. Proceedings of the Third European Symposium on Sous Vide. ALMA, Leuven, pp. 11-27.

ICMSF, 1996. Bacillus cereus. In: Roberts, T.A., Baird-Parker, A.C., Tompkin, R.B. (Eds.), 1996. Micro-Organisms in Foods: 5. Microbiological Specifications of Food Pathogens. Blackie Academic and Professional, London, pp. 20-35.

Jensen, F.V., 1996. An Introduction to Bayesian Networks UCL Press.

Johnson, K.M., Nelson, C.L., Busta, F.F., 1982. Germination and heat resistance of Bacillus cereus spores from strains associated with diarrheal and emetic food-borne illnesses. Journal of Food Science 47, 1268-1271.

Johnson, A.E., Donkin, A.J., Morgan, K., Lilley, J.M., Neale, R.J., Page, R.M., Silburn, R., 1998. Food safety knowledge and practice among elderly people living at home. Journal of Epidemiology and Community Health 52, 745-748.

Koutsoumanis, K., Nychas, G.-J.E., 2000. Application of a systematic experimental procedure to develop a microbial model for rapid fish shelf life predictions. International Journal of Food Microbiology 60, 171-184.

Litman, S.Distribution, Retail and Consumer Storage of Chilled Foods. SYNAFAP, Paris, France.

Lund, B.M., Peck, M.W., 2000. Clostridium botulinum. In: Lund, B.M., Baird-Parker, A.C., Gould, G.W. (Eds.), The Microbiological Quality and Safety of Food, vol. II, Aspen Publishers, Gaithersburg, pp. 1057-1109.

Lund, T., De Buyser, M.-L., Granum, P.E., 2000. A new cytotoxin from Bacillus cereus that may cause necrotic enteritis. Molecular Microbiology 38, 254-261.

McKillip, J.L., 2000. Prevalence and expression of enterotoxins in Bacillus cereus and other Bacillus spp., a literature review. Antonie van Leeuwenhoek 77, 393-399.

Nauta, M.J., 2001. A modular process risk model structure for quantitative microbiological risk assessment and its application in an exposure assessment of Bacillus cereus in a REPFED. 149106 007: RIVM, Bilthoven.

Nauta, M.J., 2002. Modelling bacterial growth in quantitative microbiological risk assessment: is it possible? International Journal of Food Microbiology 73, 297-304.

Nauta, M.J., Evers, E.G., Takumi, K., Havelaar, A.H., 2001. Risk assessment of Shiga toxin producing Escherichia coli $\mathrm{O} 157$ in steak tartare in the Netherlands. 257851 003: RIVM, Bilthoven.

Notermans, S., Dufrenne, J., Teunis, P., Beumer, R., Te Giffel, M., Peeters Weem, P., 1997. A risk assessment study of Bacillus cereus present in pasteurized milk. Food Microbiology 14, $143-151$.

Peck, M.W., 1999. Safety of sous-vide foods with respect to Clostridium botulinum. Proceedings of the Third European Symposium on Sous Vide. ALMA, Leuven, pp. 55-67.

Pierre, O., 1996. Température de conservation de certaines denrées alimentaires très périssables dans les rayons "libre service" des grandes et moyenne surfaces. Option Qualité 138, 12-18.

Pol, I.E., van Arendonk, W.G., Mastwijk, H.C., Krommer, J., Smid, E.J., Moezelaar, R., 2001. Sensitivities of germinating spores and carvacrol-adapted vegetative cells and spores of Bacillus cereus to nisin and pulsed-electric-field treatment. Applied and Environmental Microbiology 67, 1693-1699.

Ratkowsky, D.A., Olley, J., McMeekin, T.A., Ball, A., 1982. Relationship between temperature and growth rate of bacterial cultures. Journal of Bacteriology 149, 1-5.

Sergelidis, D., Abrahim, A., Sarimvei, A., Panoulis, C., Karaioannoglou, P., Genigeorgis, C., 1997. Temperature distribution and prevalence of Listeria spp. in domestic, retail and industrial refrigerators in Greece. International Journal of Food Microbiology 34, 171-177.

Smith, M.G., 1985. The generation time, lag time, and minimum temperature of growth of coliform organisms on meat, and the implications for codes of practice in abattoirs. Journal of Hygiene 94, 289-300.

Taoukis, P.S., Labuza, T.P., 1989. Applicability of time-temperature indicators as shelf life monitors of food products. Journal of Food Science 54, 783-788.

Taoukis, P.S., Koutsoumanis, K., Nychas, G.J., 1999. Use of timetemperature integrators and predictive modelling for shelf life control of chilled fish under dynamic storage conditions. International Journal of Food Microbiology 53, 21-31.

USDA, 1998. Pathogen Modeling Program, version 5.1.

Valero, M., Leontidis, S., Fernandez, P.S., Martinez, A., Salmeron, M.C., 2000. Growth of Bacillus cereus in natural and acidified carrot substrates over the temperature range $5-30{ }^{\circ} \mathrm{C}$. Food Microbiology 17, 605-612.

Vose, D., 2000. Risk Analysis: A Quantitative Guide, 2nd ed. Wiley, Chichester.

Whiting, R.C., 1995. Microbial modeling in foods. Critical Reviews in Food Science and Nutrition 35, 467-494.

Wijtzes, T., de Wit, J.C., Huis in't Veld, J.H.J., van't Riet, K., Zwietering, M.H., 1995. Modelling bacterial growth of Lactobacillus curvatus as a function of acidity and temperature. Applied and Environmental Microbiology 61, 2533-2539.

Zwietering, M.H., Cuppers, H.G.A.M., de Wit, J.C., van 't Riet, K., 1994. Evaluation of data transformations and validation of a model for the effect of temperature on bacterial growth. Applied and Environmental Microbiology 60, 195-203.

Zwietering, M.H., De Wit, J.C., Notermans, S., 1996. Application of predictive microbiology to estimate the number of Bacillus cereus in pasteurised milk at the point of consumption. International Journal of Food Microbiology 30, 55-70. 